\title{
ANALISIS SERTIFIKASI GURU TERHADAP KINERJA GURU PENDIDIKAN JASMANI PADA TINGKAT SMP
}

\author{
M. Imran Hasanuddin ${ }^{1}$, Normasunah ${ }^{2}$ \\ ${ }^{1}$ Prodi Penjaskesrek, STKIP Paris Berantai Kotabaru \\ Kalimantan Selatan, Indonesia \\ ${ }^{2}$ Prodi Pendidikan Bahasa dan Sastra Indonesia, STKIP Paris Berantai Kotabaru \\ Kalimantan Selatan, Indonesia \\ e-mail: mbsimran809@gmail.com, chunakhulu@gmail.com
}

\begin{abstract}
Abstrak
Penelitian ini bertujuan untuk mengetahui (1) tingkat kinerja guru Pendidikan Jasmani tersertifikasi pada tingkat SMP, (2) hubungan sertifikasi guru dengan kinerja guru Pendidikan Jasmani pada tingkat SMP, dan (3) Keterkaitan sertifikasi guru terhadap kinerja guru Pendidikan Jasmani pada tingkat SMP. Populasi dalam penelitian ini adalah Guru Pendidikan Jasmani pada tingkat SMP Negeri di Kecamatan Pulau Laut Kabupaten Kotabaru Kalimantan Selatan yang berjumlah 33 orang. Sampel dalam penelitian ini adalah Guru Pendidikan Jasmani yang sudah tersertifikasi yang berjumlah 22 orang. Teknik pengambilan sampelnya menggunakan purposive sampling. Teknik analisis data dalam penelitian ini sesuai dengan analisis statistika deskriktif dan analisis inferensial. Data yang dikumpulkan tersebut akan dianalisis dengan bantuan program SPSS versi 20.00. Hasil penelitian menunjukkan bahwa: (1) tingkat kinerja guru pendidikan jasmani tersertifiaksi berada pada kategori cukup; (2) ada hubungan yang signifikan antara sertifikasi guru dengan kinerja guru pendidikan jasmani dengan nilai $(r)$ sebesar $0.544\left(P_{\text {value }}<\alpha 0,05\right)$; dan (3) ada keterkaitan yang signifikan antara sertifikasi guru terhadap kinerja guru pendidikan jasmani dengan nilai $R_{\text {square }}$ sebesar 0.296, nilai Beta sebesar 0,544 dan nilai thitung sebesar $2.899\left(P_{\text {value }}\right.$ $<\alpha 0,05)$. Kesimpulan dari penelitian ini adalah ada hubungan yang signifikan antara sertifikasi guru dengan kinerja guru Pendidikan Jasmani tingkat SMP Negeri di Kecamatan Pulau Laut Kabupaten Kotabaru Kalimantan Selatan
\end{abstract}

Kata kunci: sertifikasi, kinerja, guru pendidikan jasmani

\begin{abstract}
This research aimed to identify (1). the level performance of the physical education teacher certification, (2) is there a relationship between teacher certification with performance of physical education teacher, (3). Is there linkages of teacher certification with performance of physical education teacher in Junior High School. The population of this study is 33 teachers of physical education at Junior High Schools in Pulau Laut District, Kotabaru Regency, South Kalimantan. The sample in this study is 22 certified physical education teachers. The sampling technique used is purposive sampling. The data analysis technique in this study is in accordance with descriptive statistical and inferential analysis. The data collected were analyzed using computer system SPSS version 20.00. The result pf this research concluded that (1). the level performance of physical education teacher certification falls in enough category. (2) There is a relationship between the teacher certification with the performance of the teacher physical education in Junior High School with the score ${ }^{\circledR} 0.544$ (Pvalue $<a$ 0.05) and (3) There is the significant linkages between teacher certification with the performance of the teacher physical education in Junior High School with the score $R_{\text {square }}$ sebesar 0.296, score Beta 0.544 and the score $t_{\text {count }} 2.899$ $\left(P_{\text {value }}<a\right.$ 0.05). The conclusion is a significant relationship between teacher certification and the performance of physical education teachers at the State Junior High School in Pulau Laut District, Kotabaru Regency, South Kalimantan.
\end{abstract}

Keywords: certification, performance, physical education teacher 


\section{PENDAHULUAN}

Guru merupakan cermin pribadi yang mulia bagi anak didiknya, yakni guru yang rela menyisihkan waktunya demi kepentingan anak didiknya, dari membimbing, mendengarkan keluhan, menasehati, bersenda gurau, dan membantu anak didiknya dalam menghadapi kesulitan yang dapat menghambat aktivitas belajarnya. Sebagai tenaga pengajar/pendidik, guru merupakan salah satu faktor penentu keberhasilan setiap upaya pendidikan. Itulah sebabnya dalam setiap inovasi pendidikan, khususnya dalam perbaikan kurikulum, selalu bermuara pada faktor guru. Guru merupakan ujung tombak dalam pembangunan pendidikan nasional, utamanya dalam membangun dan meningkatkan kualitas sumberdaya manusia melalui pendidikan formal.

Peran guru sebagai tenaga profesional bukan hanya untuk mendidik, mengajar, membimbing, mengarahkan, melatih, dan mengevaluasi peserta didik, tetapi juga berkaitan dengan kepribadian yang dapat menjadi pemicu keberhasilan peserta didik. Kepribadian guru dapat mempengaruhi suasana kelas yaitu kepribadian yang dapat memberikan kebebasan yang dinikmati anak didik dalam mengeluarkan buah pikirannya maupun mengembangkan kreatifitasnya. Namun, kebebasan guru juga terbatas oleh pribadi atasannya (Kepala Sekolah, Pengawas, Kakanwil, sampai Mendikbud). Keseluruhannya dipengaruhi, dibatasi, serta diarahkan pada tujuan pendidikan nasional, (Gunawan, 2010).

Sertifikasi guru adalah proses pemberian sertifikat pendidik bagi guru/calon guru yang telah memenuhi persyaratan dan lulus uji kompetensi (Mudlofir, 2012:117). Program ini ternyata dapat dikatakan sebagai salah satu motivasi bagi seorang guru untuk dapat meningkatkan kinerjanya dalam bekerja. Pelaksanaan program sertifikasi guru dilaksanakan sejak tahun 2007 setelah diterbitkannya Peraturan Mendiknas Nomor 18 Tahun 2007 tentang Sertifikasi Bagi Guru Dalam Jabatan. Melalui sertifikasi ini guru dituntut agar bersungguh-sungguh menjalankan tugasnya sebagai guru dan mengerahkan segala pemikiran serta kreatifitasnya bagi pendidikan. Kinerja guru sangat dibutuhkan dalam proses mengajar. Dalam meningkatkan kinerja seorang guru, guru harus mengikuti suatu program yaitu program sertifikasi. Oleh karena itu, dalam pembaharuan proses pendidikan tersebut maka dibutuhkan kinerja guru yang sangat tinggi. Bahri (2011) menyebutkan bahwa kinerja guru dapat dipengaruhi oleh kemampuan guru dalam mengajar, persepsi guru tentang lingkungan kerja serta motivasi guru dalam kerja secara bersama-sama.

Dalam Undang Undang Republik Indonesia Nomor 14 tahun 2005 tentang Guru dan Dosen, dikemukakan bahwa sertifikasi adalah proses pemberian sertifikat pendidik untuk guru dan dosen. Sedangkan sertifikat pendidikan adalah bukti formal sebagai pengakuan yang diberikan kepada guru dan dosen sebaga tenaga profesional. Berdasarkan pengertian tersebut, dapat disimpulkan bahwa sertifikasi guru adalah proses pemberian pengakuan bahwa seseorang telah memiliki kompetensi untuk melaksanakan pelayanan pendidikan pada satuan pendidikan tertentu, setelah lulus uji kompetensi yang diselenggarakan oleh lembaga sertifikasi. Dengan kata lain, sertifikasi guru adalah proses uji kompetensi seseorang sebagai landasan pemberian sertifikast pendidik. Sesuai Peraturan Menteri Pendidikan Nasional RI Nomor 18 tahun 2007 tentang sertifikasi guru dalam jabatan, komponen portofilio meliputi: (a) kualifikasi akademik, (b) pendidikan dan pelatihan, (c) prestasi akademik, (d) karya pengembangan profesi, dan (5) keikutsertaan dalam forum ilmiah.

Di sekolah kinerja guru dioptimalkan dengan baik melalui pengaturan program pelatihan untuk para guru sehingga mereka akan termotivasi dan akan dapat meningkat kinerjanya (Inayatullah \& Jehangir, 2012). Tingkat keberhasilan guru diperoleh melalui penilaian kinerja guru (PKG) yang dilaksanakan setiap tahun berdasarkan Peraturan Menteri Pendidikan Nasional No. 16 Tahun 2007 tentang Standar Kualifikasi Akademik dan Kompetensi Guru. Penilaian tentang kinerja guru ini dibuat dengan tujuan utama untuk mengetahui seberapa paham guru dalam mengaplikasikan kompetensi 
pedagogik, kepribadian, sosial, dan professional (Salmawati et al., 2017). Kompetensi tersebut wajib dipenuhi oleh guru sebagai acuan dalam keberhasilan belajar mengajar. Dengan adanya hal mengenai kompetensi guru, kelemahan-kelemahan dapat di identifikasi antara lain: dalam menambahkan pengetahuan menyeluruh tentang materi pelajaran, merumuskan pertanyaan untuk mengklarifikasi pelajaran, penggunaan berbagai bantuan untuk membuat materi pelajaran dalam modul lebih menarik, dan memberikan tugas yang menantang yang berlaku untuk situasi kehidupan nyata.

Kinerja Guru pada dasarnya merupakan kinerja atau unjuk kerja yang dilakukan oleh guru dalam melaksanakan tugasnya sebagai pendidik. Kinerja guru sangat menentukan kualitas hasil pendidikan, karena guru merupakan pihak yang paling banyak bersentuhan langsung dengan siswa dalam proses pendidikan/ pembelajaran (Fuad, 2017). Sesuai dengan pengalaman emperis sebagai peneliti sekaligus dosen program studi pendidikan jasmani di STKIP Paris Barantai Kotabaru selama 4 tahun mengamati bahwa sertifikasi guru saat ini di Kabupaten Kotabaru Kalimantan Selatan khususnya di Kecamatan Pulau Laut ternyata belum menunjukkan adanya perubahan secara nyata kearah yang lebih baik. Untuk itu perlu diadakan perbaikan sistem sertifikasi agar dapat menunjukkan hasil yang lebih nyata. Seperti harapannya bahwa tujuan utama diadakan program sertifikasi adalah untuk meningkatkan pengetahuan, kinerja, kreatifitas, serta mampu menjalankan fungsi-fungsi lainnya yang berhubungan dengan proses belajar mengajar. Berdasarkan latar belakang masalah di atas, peneliti tertarik untuk mengungkapkan fenomena ini ke dalam sebuah bentuk penelitian. Tujuan dilakukannya penelitian ini adalah untuk mengetahui hubungan sertifikasi yang telah didapatkan guru terhadap kinerja guru.

\section{METODE}

Jenis penelitian ini menggunakan metode penelitian kuantitatif korelasional. Menurut Sugiyono (2019), penelitian kuantitatif dapat diartikan sebagai metode penelitian yang berlandaskan pada filsafat positivism, digunakan untuk meneliti pada populasi atau sampel tertentu, pengumpulan data menggunakan instrumen penelitian, analisis data bersifat kuantitatif/ statistik, dengan tujuan untuk menguji hipotesis yang telah ditetapkan.

Populasi dalam penelitian ini adalah Guru Pendidikan Jasmani pada tingkat SMP Negeri di Kecamatan Pulau Laut Kabupaten Kotabaru Kalimantan Selatan yang berjumlah 33 orang. Sedangkan sampel dalam penelitian ini adalah Guru Pendidikan Jasmani yang sudah tersertifikasi pada tingkat SMP Negeri di Kecamatan Pulau Laut Kabupaten Kotabaru Kalimantan Selatan yang berjumlah 22 orang. Teknik pengambilan sampelnya menggunakan purposive sampling.

Teknik pengumpulan datanya berlangsung selama 21 kali pertemuan, yaitu dengan perincian waktu 1 kali pertemuan untuk 1 sekolah, dengan jumlah waktu pertemuan 120 menit. Instrumen penelitian yang digunakan dalam penelitian ini adalah Format Penilaian Kinerja Guru (PKG) Guru Kelas/Guru Mata Pelajaran yang bersumber dari:

a. Peraturan Menteri Pendidikan Nasional Nomor 16 Tahun 2007 tentang Standar Kualifikas Akademik dan KompetensiGuru.

b. BSNP versi 6.0. 11Tahun 2008 tentang Kerangka Indikator untuk Pelaporan Pencapaian Standar Nasional Pendidikan: Standar Kualifikasi Akademik dan KompetensiGuru.

c. Permenneg PAN dan RB Nomor 16 Tahun 2009 tentang Jabatan Fungsional Guru dan Angka Kreditnya.

Teknik analisis data disesuaikan dengan pertanyaan dan hipotesis penelitian. Pertanyaan dan hipotesis yang diajukan dalam penelitian ini sesuai dengan analisis statistika deskriktif dan analisis inferensial meliputi uji normalitas data, uji korelasi dan 
ISSN 2356-3397 (Print) | ISSN 2597-4505 (Online)

uji regresi sederhana. Analisis data menggunakan bantuan sistem komputer pada program SPSS versi 20.00.

\section{HASIL DAN PEMBAHASAN \\ Hasil}

Hasil penelitian ini dianalisis dengan statistik deskriptif dan statistik parametrik meliputi teknik korelasional dan regresi sesuai tujuan penelitian ini untuk mengetahui korelasi sertifikasi guru terhadap kinerja guru Pendidikan Jasmani pada tingkat SMP Negeri di Kecamatan Pulau Laut Kabupaten Kotabaru Kalimantan Selatan.

1. Hasil Analisis Deskriptif Data Sertifikasi Guru dan Kinerja Guru Pendidikan Jasmani.

Hasil analisis deskriptif data sertifikasi guru dan kinerja guru pendidikan jasmani secara lengkap dapat dilihat pada tabel 1.

Tabel 1. Hasil Analisis Deskriptif Data Variabel Sertifikasi Guru dan Kinerja Guru Pendidikan Jasmani

\begin{tabular}{ccccc}
\hline Variabel & Mean & SD & Min & Max \\
\hline Sertifikasi Guru & 56.86 & 6.84 & 42 & 68 \\
Kinerja Guru & 83.64 & 2.51 & 80 & 88 \\
\hline
\end{tabular}

Berdasarkan tabel 1 di atas dapat dilihat bahwa dari variable sertifikasi guru dengan rata-rata sebesar 56.86, nilai standar deviasi sebesar 6.84 , nilai minimum sebesar 42 , dan nilai maksimum sebesar 68 . Sedangkan hasil analisis deskriptif data kinerja guru diperoleh nilai rata-rata sebesar 83.64, nilai standar deviasi sebesar 2.51, nilai minimum sebesar 80 , dan nilai maksimum sebesar 88 .

2. Hasil Analisis Kategori Data Kinerja Guru Pendidikan Jasmani Tersertifikasi.

Hasil analisis kategori data kinerja guru Pendidikan Jasmani tersertifikasi dapat dilihat pada tabel 2 berikut.

Tabel 2. Persentase Kategori Data Kinerja Guru Tersertifikasi.

\begin{tabular}{|c|c|c|c|c|}
\hline No. & Interval & $\mathbf{F}$ & $\%$ & Kategori \\
\hline 1 & $86-91$ & 7 & 32 & Baik \\
\hline 2 & $80-85$ & 15 & 68 & Cukup \\
\hline \multicolumn{2}{|c|}{ Total } & 22 & 100 & \\
\hline
\end{tabular}

Berdasarkan tabel 2, dapat disimpulkan bahwa dari hasil persentase kategori data kinerja guru Pendidikan Jasmani tersertifikasi diketahui bahwa ada 7 orang atau $32 \%$ yang termasuk kategori baik, dan 15 orang atau $68 \%$ yang termasuk kategori cukup. Dengan demikian secara keseluruhan dapat dikatakan bahwa kinerja guru Pendidikan Jasmani berada pada kategori cukup.

\section{Pengujian Normalitas Data}

Teknik pengujian normalitas data tiap variabel dalam penelitian ini yaitu dengan menggunakan metode analisis uji normalitas Lilliefors Significance Correction. Berdasarkan hasil uji normalitas data, adapun hasil pengujian yang diperoleh dapat dirangkum dalam tabel 3. 
ISSN 2356-3397 (Print) | ISSN 2597-4505 (Online)

Tabel 3. Hasil Uji Normalitas Data Sertifikasi Guru dan Kinerja Guru Pendidikan Jasmani

\begin{tabular}{|c|c|c|c|}
\hline \multirow[t]{2}{*}{ Variabel } & \multicolumn{3}{|c|}{ Shapiro-Wilk } \\
\hline & Statistik & df & Sig. \\
\hline Sertifikasi Guru & 0.962 & 22 & 0.530 \\
\hline $\begin{array}{l}\text { Kinerja Guru } \\
\text { Pendidikan Jasmani }\end{array}$ & 0.919 & 22 & 0.071 \\
\hline
\end{tabular}

Berdasarkan table 3 di atas, maka dapat terlihat bahwa dari hasil pengujian normalitas data dengan menggunakan uji Lilliefors Significance Correction, menunjukkan hasil sebagai berikut:

a. Untuk data sertifikasi guru, diperoleh nilai statistik Shapiro- Wilk sebesar 0.962 (Sig. $0.530>\alpha 0.05)$, sehingga dapat disimpulkan bahwa data sertifikasi guru berdistribusi normal.

b. Untuk data kinerja guru Pendidikan Jasmani, diperoleh nilai statistik Shapiro-Wilk sebesar 0.919 (Sig $0.071>\alpha 0.05$ ), sehingga dapat disimpulkan bahwa data kinerja guru Pendidikan Jasmani berdistribusi normal.

4. Analisis Korelasi

Untuk mengetahui keeratan korelasi sertifikasi guru terhadap kinerja guru Pendidikan Jasmani dilakukan perhitungan nilai korelasi dari Pearson ( $r$ ) pada tingkat signifikansi 5\%. Adapun rangkuman hasil perhitungannya dapat dilihat padaTabel 4.

Tabel 4. Hasil Analisis Korelasi Antara Sertifikasi Guru Terhadap Kinerja Guru Pendidikan Jasmani

\begin{tabular}{cccc}
\hline Variabel Penelitian & N & $\begin{array}{c}\text { Pearson } \\
\text { Correlations }\end{array}$ & Sig. \\
\hline $\begin{array}{c}\text { Sertifikasi Guru }(X) \text { terhadap } \\
\text { Kinerja Guru Pendidikan } \\
\text { Jasmani (Y) }\end{array}$ & 22 & 0.544 & 0.009 \\
\hline
\end{tabular}

Berdasarkan table 4 di atas, terlihat bahwa hasil perhitungan nilai korelasi menggunakan uji korelasi menggunakan uji pearson diperoleh diperoleh nilai $r=0.544$ $(P \leq \alpha 0,05)$ dapat diartikan bahwa ada korelasi sertifikasi guru terhadap kinerja guru Pendidikan Jasmani pada tingkat SMP Negeri di Kecamatan Pulau Laut Kabupaten Kotabaru Kalimantan Selatan.

\section{Analisis Regresi}

Analisis regresi linear sederhana untuk mengetahui keterkaitan sertifikasi guru terhadap kinerja guru Pendidikan Jasmani dilakukan melalui analisis regresi pada tingkat signifikansi $5 \%$. Adapun hasil perhitungan secara lengkap pada rangkuman hasil analisisnya dapat dilihat pada Tabel 5 berikut ini.

Tabel 5. Hasil Analisis Regresi Linear Sederhana Antara Sertifikasi Guru Terhadap Kinerja Guru Pendidikan Jasmani

\begin{tabular}{cccc}
\hline Model & B & Beta & t \\
\hline (Constant) & 72.264 & - & 18.296 \\
Sertifikasi Guru & 0.2000 & 0.544 & 2.899 \\
\hline
\end{tabular}


ISSN 2356-3397 (Print) | ISSN 2597-4505 (Online)

6. Dependen Variabel: Kinerja Guru Pendidikan Jasmani

Berdasarkan tabel tersebut di atas dapat didapat $t$ persamaan perhitungan sebagai berikut: $Y=106.284+1.091 \mathrm{X}$

Dimana $Y=$ Kinerja Guru Pendidikan Jasmani dan $X=$ Sertifikasi Guru.

Nilai 72.264 merupakan nilai kosntanta (a) yang menunjukkan bahwa jika tidak ada kenaikan sertifikasi guru, maka kinerja guru Pendidikan Jasmani akan mencapai 72.264. Sedangkan harga $0.200 \mathrm{X}$ merupakan koefisien regresi yang menunjukkan bahwa setiap ada penambahan 1 nilai/angka untuk kecerdasan emosional, maka akan ada kenaikan kinerja guru Pendidikan Jasmani sebesar 0.200.

Angka 0.544 pada Standardized Coefficient (Beta) menunjukkan tingkat korelasi antara sertifikasi guru dengan kinerja guru Pendidikan Jasmani. Nilai t merupakan nilai yang berguna untuk pengujian, apakah keterkaitan sertifikasi guru terhadap kinerja guru Pendidikan Jasmani benar-benar signifikan atau tidak. Dapat disimpulkan bahwa nilai $t_{\text {titung }}=2.899$ dan sig $(p)=0.009$. Di mana $(p)=0.009<0.05$. Jadi, terdapat keterkaitan sertifikasi guru terhadap kinerja guru Pendidikan Jasmani.

\section{Pembahasan}

Berdasarkan hasil penelitian terhadap data kinerja guru Pendidikan Jasmani tingkat SMP Negeri se-Kecamatan Pulau Laut Kabupaten Kotabaru Kalimantan Selatan yang sudah bersertifikasi pendidik diperoleh data bahwa $32 \%$ (7 orang) berada dalam kategori bekinerja baik dan sisanya 68\% (15 orang) masih dalam kategori cukup. Temuan ini mengindikasikan bahwa walaupun guru sudah bersertifikasi masih banyak yang belum menunjukkan kinerja yang maksimal. Hal ini sejalan dengan penelitian yang dilakukan oleh Kartowagiran (2011) bahwa kinerja guru pasca sertifikasi belum memuaskan dengan fakta dari 17 indikator dimana 10 indikator kinerja masih dalam karegori cukup atau sedang. Guru masih perlu mendapatkan bimbingan yang berkelanjutkan meski sudah lulus sertifikasi terutama pada aspek penulisan karya dan kegiatan ilmiah.

Hasil penelitian juga menunjukkan adanya hubungan yang signifikan antara sertifikasi guru terhadap kinerja guru Pendidikan Jasmani tingkat SMP Negeri seKecamatan Pulau Laut Kabupaten Kotabaru Kalimantan Selatan dengan hasil analisis nilai regresi linier sederhana yaitu $t=2.899$ da sig. $(p)=0.009$. Dimana kinerja guru mengalami peningkatan dengan adanya sertifikasi bagi guru. Hal ini senada dengan penelitian yang dilakukan oleh Jaenudin (2017) bahwa ada pengaruh antara program sertifikasi guru dengan kinerja guru Penjasorkes di Kabupaten Sumedang. Program sertifikasi memebrikan pengaruh sebesar $80,5 \%$ terhadap kinerja guru. Penelitian lainnya dilakukan oleh Damanik et al (2016) mengenai kinerja guru Penjasorkes yang sudah tersertifikasi di UPTD Percut Sei Tuan menunjukkan hasil bahwa dari aspek rencana pembelajaran penjasorkes berada pada kategori baik, pelaksanaan pembelajaran penjasorkes berada pada kategori baik, mendemonstrasikan berada pada kategori baik, penilaian evaluasi dalam penjasorkes berada pada kategori baik. Hasil penelitian tersebut menyimpulkan bahwa sertifikasi guru berdampak besar terhadap kinerja guru khususnya guru Penjasorkes.

Program sertifikasi bagi guru dimaksudkan untuk memenuhi standar profesional guru. Sertifikasi merupakan proses pemberian pengakuan bahwa seorang telah memiliki kompetensi untuk melaksanakan pelayanan pendidikan pada satuan pendidikan tertentu, setelah lulus di uji kompetensi yang diselenggarakan oleh lembaga sertifikasi (Koswara \& Rasto, 2016). Guru profesional adalah syarat wajib untuk menciptakan sistem dan praktik pendidikan yang berkualitas. Dengan guru yang professional diharapkan guru memiliki kompetensi yang baik serta menunjukkan kinerja yang baik juga. Beberapa hasil penelitian menunjukkan bahwa ada hubungan dan pengaruh yang positif antara sertifikasi guru dengan kinerja guru. Seperti penelitian 
yang dilakukan oleh Zulkifli et al (2014) yang menunjukkan bahwa ada hubungan yang positif antara sertifikasi guru dengan kinerja guru. Tunjangan profesi yang diberikan berdampak positif terhadap kesejahteraan guru, dimana kesejahteraan meningkatkan motivasi dan motivasi dapat meningkatkan kinerja. Kartini \& Kristiawan (2019) melakukan penelitian mengenai pengaruh tunjangan profesi dan motivasi terhadap keinerja guru, dengan hasil menunjukkan bahwa $25,3 \%$ kinerja guru dipengaruhi oleh pemberian tunjangan profesi sedangkan sisanya $74,7 \%$ ditentukan faktor lainnya. Hal ini sejalan dengan penelitian yang dilakukan oleh Koswara \& Rasto (2016) sertifikasi guru memberikan dampak yang positif terhadap peningkatan kompetensi dan kinerja guru. Hasil penelitian menunjukkan ada perbedaan kinerja yang signifikan antara guru yang sudah bersertifikasi dan yang belum bersertifikasi.

\section{SIMPULAN DAN SARAN Simpulan}

Berdasarkan hasil pengujian hipotesis dan pembahasan hasil penelitian, dapat ditarik sebuah kesimpulan yaitu bahwa tingkat kinerja guru bersertifikasi berada dalam kategori cukup, terdapat hubungan dan keterkaitan antara sertifikasi guru dengan kinerja guru Pendidikan Jasmani tingkat SMP Negeri se-Kecamatan Pulau Laut Kabupaten Kotabaru Kalimantan Selatan

\section{Saran} berikut:

Berdasarkan kesimpulan penelitian ini dikemukakan beberapa saran sebagai

1. Bagi kepala sekolah agar lebih memperthatikan dan dapat membimbing guru pendidikan jasmani untuk dapat meningkatkan keprofesionalan guru khususnya untuk guru yangbersertifikasi.

2. Sebagai bahan masukan dan informasi bagi guru yang bersertifikasi agar dapat lebih meningkatkan kualitas dalam pembelajaran pendidikanjasmani.

3. Bagi peneliti selanjutnya hendaknya menggunakan sampel yang lebih besar serta menambahkan variabel- variabel yang lain untuk diteliti sehingga pembahasan akan lebih luas dan hasil penelitian yang didapat lebihmaksimal.

\section{DAFTAR PUSTAKA}

Bahri, S. (2011). Faktor yang mempengaruhi Kinerja Guru SD di Dataran Tinggimoncong Kabupaten Gowa Provinsi Sulawesi Selatan. Jurnal Medtek, 3(2), 1-11.

Damanik, S. A., Fadli, Z., \& Suyono, H. (2016). Kinerja Guru Pendidikan Jasmani Kesehatan Olahraga yang Sudah Disertifikasi. Jurnal Penelitian Bidang Pendidikan, 22(2), 139-148.

Fuad, N. (2017). Pengaruh Sertifikasi Guru terhadap Peningkatan Kinerja Guru PAI di SMP dan MTS. Jurnal Manajemen Pendidikan, 8(1), 23-32.

Gunawan, A. H. (2010). Sosiologi Pendidikan: Suatu Analisis Sosiologi tentang Pelbagai Problem Pendidikan. Rineka Cipta.

Inayatullah, A., \& Jehangir, P. (2012). Teacher's job Performance: The Role of Motivation. Abasyn Journal of Social Sciences, 5(2), 78-99.

Jaenudin, J. (2017). Pengaruh Program Sertifikasi dan Kompetensi Terhadap Kinerja Guru Penjasorkes SMP Negeri se-Kabupaten Sumedang. Administrasi Pendidikan: Jurnal Ilmiah Mahasiswa Pascasarjana, 2(1), 31-36.

Kartini, D., \& Kristiawan, M. (2019). Pengaruh Tunjangan Profesi dan Motivasi Kerja Terhadap Kinerja Guru. Kelola: Jurnal Manajemen Pendidikan, 6(1), 25-33. 
Kartowagiran, B. (2011). Kinerja Guru Profesional (Guru pasca sertifikasi). Jurnal Cakrawala Pendidikan, 3(3).

Koswara, K., \& Rasto, R. (2016). Kompetensi dan Kinerja Guru Berdasarkan Sertifikasi Profesi. Jurnal Pendidikan Manajemen Perkantoran (JPManper), 1(1), 61-71.

Mudlofir, A. (2012). Pendidik Profesional: Konsep, Strategi dan Aplikasinya dalam Peningkatan Mutu Pendidik di Indonesia. PT Raja Grafindo.

Salmawati, S., Rahayu, T., \& Lestari, W. (2017). Kontribusi Kompetensi Pedagogik, Kompetensi Profesional dan Motivasi Kerja terhadap Kinerja Guru Penjasorkes SMP di Kabupaten Pati. Journal of Physical Education and Sports, 6(2), 198-204.

Sugiyono. (2019). Metode Penelitian Kuantitatif, Kualitatif, dan R\&D. Alfabeta.

Zulkifli, M., Darmawan, A., \& Sutrisno, E. (2014). Motivasi Kerja, Sertifikasi, Kesejahteraan dan Kinerja Guru. Persona: Jurnal Psikologi Indonesia, 3(02). 